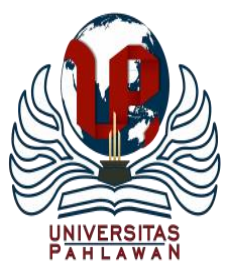

Jurnal Abdidas Volume 2 Nomor 4 Tahun 2021 Halaman 737-742

JURNAL ABDIDAS

http://abdidas.org/index.php/abdidas

\title{
Pelatihan Pemanfaatan Sistem Informasi Pelaporan Retribusi Sampah
}

\author{
Nuraida Latif ${ }^{1}$, Syaharullah Disa ${ }^{2}$, Ratnawati $^{3}$, Agus Halid $^{4}$, Andi Sumardin ${ }^{5}$, A.Yulia Muniar ${ }^{6}$, Wisda $^{7}$ \\ Teknik Informatika, STMIK AKBA, Makassar, Indonesia, 1,2,4 \\ Sistem Informasi, STMIK AKBA, Makassar, Indonesia ${ }^{3,5,6,7}$ \\ E-mail : nuraida@akba.ac.id ${ }^{1}$, syaharullah@akba.ac.id ${ }^{2}{ }_{2}$ ratnawati@akba.ac.id $^{3}{ }_{2}$ agushalid@akba.ac.id ${ }^{4}$, \\ andisumardin@akba.ac.id ${ }^{5}$, andiyulia@akba.ac.id ${ }^{6}$, wisda@akba.ac.id ${ }^{7}$
}

\begin{abstract}
Abstrak
Sistem pelaporan retribusi sampah yang ada saat ini di Kecamatan Manggala Kota Makassar, masih menggunakan sistem pelaporan retribusi sampah secara manual, yaitu pada saat pelaporan retribusi sampah dilaporkan pada petugas penagih retribusi sampah, dan harus melakukan pelaporan langsung ke kepala seksi kebersihan dengan membawa catatan hasil laporan tagihan retribusi sampah yang ditulis secara manual. Hal ini akan mempersulit proses pelaporan terhadap penagih yang dilakukan setiap bulan, karena data tidak sesuai hasil dari tagihan yang dicatat dilapangan karena sering terjadi kehilangan data. Oleh karena itu perlu adanya sistem untuk memudahkan penagih retribusi sampah dan mengefisienkan waktu dan biaya, sehingga proses pelaporan retribusi sampah lebih efiseian dibandingkan dengan pelaporan secara manual. Metode yang digunakan dalam kegiatan ini adalah metode ceramah dan metode tutorial. Hasil dari pengabdian masyarakat ini yaitu para pegawai kebersihan \& pertanaman sangat merespon dengan adanya sistem informasi pelaporan retribusi sampah yaitu mereka langsung mengimplementasikan di Kantor Kelurahan Manggala untuk pelaporan retribusi sampah.
\end{abstract}

Kata kunci: sistem informasi, kecamatan, pengabdian masyarakat

\section{Abstract}

The current waste retribution reporting system in Manggala Subdistrict, Makassar City, still uses a manual waste retribution reporting system, namely when reporting the waste retribution is reported to the garbage retribution collector, and must report directly to the head of the cleaning section by bringing a record of the report results. garbage retribution bill written manually. This will complicate the reporting process to billers which is carried out every month, because the data does not match the results of the bills recorded in the field because data loss often occurs. Therefore, it is necessary to have a system to make it easier for waste retribution collectors and to streamline time and costs, so that the waste retribution reporting process is more efficient than manual reporting. The method used in this activity is the lecture method and the tutorial method. This community service can help employees of the cleaning and planting division of the Manggala District to understand the steps for using the waste retribution reporting information system.

Keywords: information system, districts, community service

Copyright (c) 2021 Nuraida Latif, Syaharullah Disa, Ratnawati, Agus Halid, Andi Sumardin,

A.Yulia Muniar, Wisda

$\triangle$ Corresponding author

Address : Jln Perintis Kemerdekaan Km 9 no 75 Makassar

Email : nuraida@akba.ac.id

DOI : $\quad$ https://doi.org/10.31004/abdidas.v2i4.357

ISSN 2721- 9224 (Media Cetak)

ISSN 2721- 9216 (Media Online) 
738 Pelatihan Pemanfaatan Sistem Informasi Pelaporan Retribusi Sampah - Nuraida Latif, Syaharullah Disa, Ratnawati, Agus Halid, Andi Sumardin, A.Yulia Muniar, Wisda

DOI: https://doi.org/10.31004/abdidas.v2i4.357

\section{PENDAHULUAN}

Kantor Camat Kecamatan Manggala Kota Makassar Sulawesi Selatan merupakan salah satu instansi pemerintah yang melaksanakan sebagian kewenangan pemerintah Kota Makassar di wilayah kerja masing-masing, yang mencakup bidang pemerintahan, ekonomi serta pembangunan. Salah satu kewenangan atau tugas Kecamatan Manggala yang diberikan pemerintah Kota Makassar yaitu mengelolah sampah untuk memaksimalkan sumber daya dan fasilitas yang ada di Kecamatan Manggala dalam menjaga dan memelihara kebersihan di wilayah kerja Kecamatan Manggala Kota Makassar (Makassar, 2011).

Pencatatan dan pelaporan retribusi sampah merupakan kewajiban yang harus terpenuhi pada Kecamatan Manggala. Di mana pencatatan dan pelaporan retribusi sampah ini mempunyai peranan penting pada bagian pengelolah sampah kecamatan manggala kota makassar. Sistem Pencatatan dan pelaporan retribusi sampah yang tertata dengan baik, dan akan membuat memenajemen pelaporan yang lebih efisien. Para penagih pun dapat melakukan aktivitas dengan maksimal sesuai jam kerja yang telah ditetapkan (Makassar, 2011).

Sistem pencatatan dan pelaporan retribusi sampah yang ada saat ini di Kecamatan Manggala Kota Makassar, masih menggunakan sistem pencatatan dan pelaporan retribusi sampah secara manual, yaitu pada saat pelaporan retribusi sampah dilaporkan pada petugas penagih retribusi sampah, dan harus melakukan pelaporan langsung ke kepala seksi kebersihan dengan membawa catatan hasil laporan tagihan retribusi sampah yang ditulis secara manual. Hal ini akan mempersulit proses pelaporan terhadap penagih yang dilakukan setiap bulan, karena data tidak sesuai hasil dari tagihan yang di catat dilapangan karna sering terjadi kehilangan data. oleh karena itu perlu adanya pemamfaatan teknologi dan informasi dalam penagihan retribusi sampah daerah kerja Kecamatan Manggala kota Makassar untuk memudahkan penagi retribusi sampah dan mengefisienkan waktu dan biaya.

\section{METODE}

\section{Kerangka Pemecahan Masalah}

Sistem pencatatan dan pelaporan retribusi sampah yang ada saat ini di kecamatan manggala kota makassar, masih menggunakan sistem pencatatan dan pelaporan retribusi sampah secara manual, yaitu pada saat pelaporan retribusi sampah dilaporkan pada petugas penagih retribusi sampah, dan harus melakukan pelaporan langsung ke kepala seksi kebersihan dengan membawa catatan hasil laporan tagihan retribusi sampah yang ditulis secara manual. Hal ini akan mempersulit proses pelaporan terhadap penagih yang dilakukan setiap bulan, karena data tidak sesuai hasil dari tagihan yang di catat dilapangan karna sering terjadi kehilangan data. oleh karena itu perlu adanya pemamfaatan teknologi dan informasi dalam penagihan retribusi sampah daerah kerja kecamatan manggala kota Makassar untuk memudahkan penagi retribusi sampah dan mengefisienkan waktu dan biaya.

\section{Khalayak Sasaran Strategi}

Khalayak sasaran dari kegiatan ini adalah pegawai bagian kebersihan dan pertanaman 
739 Pelatihan Pemanfaatan Sistem Informasi Pelaporan Retribusi Sampah - Nuraida Latif, Syaharullah Disa, Ratnawati, Agus Halid, Andi Sumardin, A.Yulia Muniar, Wisda

DOI: https://doi.org/10.31004/abdidas.v2i4.357

Kecamatan Manggala. Sistem Informasi ini akan mempermudah pelaporan penagih retribusi sampah kepada pihak istansi pemerintah, dan menghapus penggunaan kertas kuitansi retribusi sampah yang dipakai secara manual serta memudahkan pengolahan data dan administrasi retribusi sampah.

\section{Keterkaitan}

Kegiatan ini dipandang tepat dan memiliki keterkaitan dengan khalayak sasaran yaitu pegawai bagian kebersihan \& pertanaman Kecamatan Manggala. Pegawai tersebut merupakan orang yang berperan penting dalam proses penagihan retribusi sampah.

\section{Metode Kegiatan}

Metode kegiatan yang dilakukan adalah presentasi pemanfaatan sistem informasi pelaporan retribusi sampah. Pertama dijelaskan bagaimana pentingnya penggunaan sistem informasi pelaporan retribusi sampah dalam mempermudah pelaporan pegawai kebersihan dan pertanaman Kecamatan Manggala dalam pengelolaan retribusi sampah yang transparansi.

\section{Rancangan Evaluasi}

Evaluasi keberhasilan dari kegiatan ini adalah Kasie kebersihan \& pertanaman , pegawai Kecamatan Manggala khususnya bagian kebersihan, dan pertanaman yang bertugas sebagai admin sudah bisa menjalankan sistem informasi untuk pelaporan retribusi sampah di Kecamatan Manggala. Indikator keberhasilan kegiatan ini dilihat dari respon positif dari para peserta melalui evaluasi yang diberikan. Evaluasi kegiatan juga dilakukan berupa kuesioner yang diisi peserta, terkait dengan kegiatan yang telah diikuti. Kemampuan pemahaman peserta diperoleh berdasarkan hasil evaluasi terhadap pegawai Kecamatan Manggala. Peserta akan diberikan sertifikat sebagai bukti ke ikut sertaan dalam kegiatan ini.

\section{Tempat, Waktu dan Susunan Acara}

Berikut waktu dan lokasi pelaksanaan pengabdian Masyarakat di Kecamatan Manggala :

Hari/ Tanggal : Kamis, 17 Juni 2021

Waktu $\quad: 09.00-14.30$ wita

Alamat : Jln. Bitoa Raya No 1 Perumnas Antang

Susunan Acara pada pengabdian masysrakat di Kelurahan Manggala :

a. Pembukaan

b. Sambutan dari Ketua P3M STMIK AKBA dan Kasie Kebersihan \& Pertanaman Kecamatan Manggala.

c. Penyampaian materi Pemanfaatan Sistem Informasi Pelaporan Retribusi Sampah

d. Diskusi dan Tanya Jawab

e. Penutup

\section{HASIL DAN PEMBAHASAN}

\section{Pelaksanaan Kegiatan}

Kegiatan pengabdian masysrakat yang dilakukan di Kecamatan Manggala diikuti oleh 12 peserta berjalan sesuai dengan rencana kegiatan. Sebelum dimulai kegiatan pengenalan sistem informasi, terlebih dahulu perkenalan kepada peserta yang ikut dalam pengabdian ini. Pembukaan oleh ketua P3M STMIK AKBA, 
740 Pelatihan Pemanfaatan Sistem Informasi Pelaporan Retribusi Sampah - Nuraida Latif, Syaharullah Disa, Ratnawati, Agus Halid, Andi Sumardin, A.Yulia Muniar, Wisda

DOI: https://doi.org/10.31004/abdidas.v2i4.357

disusul sambutan dari Bapak Kasie Kebersihan \&

Pertanaman Kecamatan Manggala.

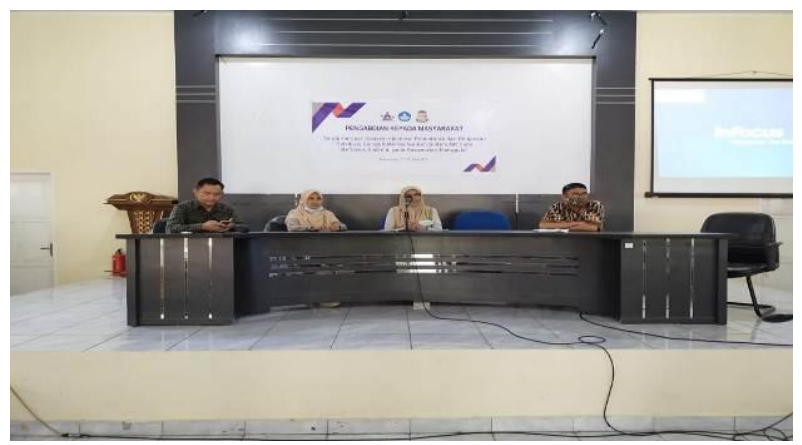

Gambar 1. Pembukaan Kegiatan

Setelah sambutan maka dilanjutkan dengan presentasi materi mengenai Sistem Informasi Pelaporan Retribusi sampah. Tampilan dari sistem pelaporan retribusi sampah yang di presentasi dalam materi mulai dari tampilan awal sistem untuk login seperti gambar 2.

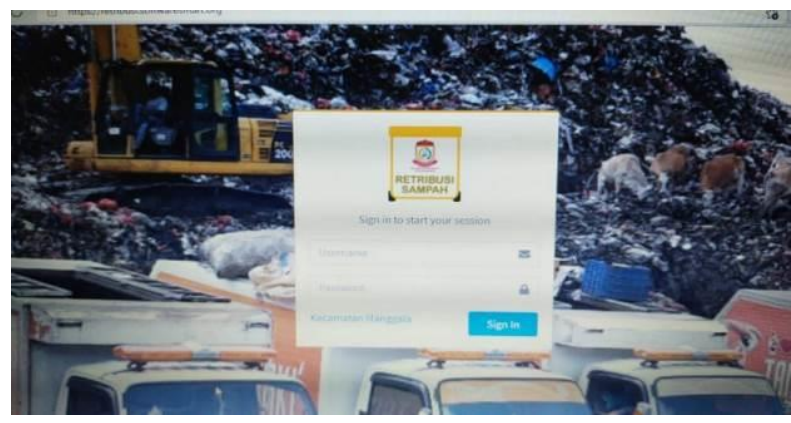

Gambar 2. Tampilan awal untuk login ke sistem

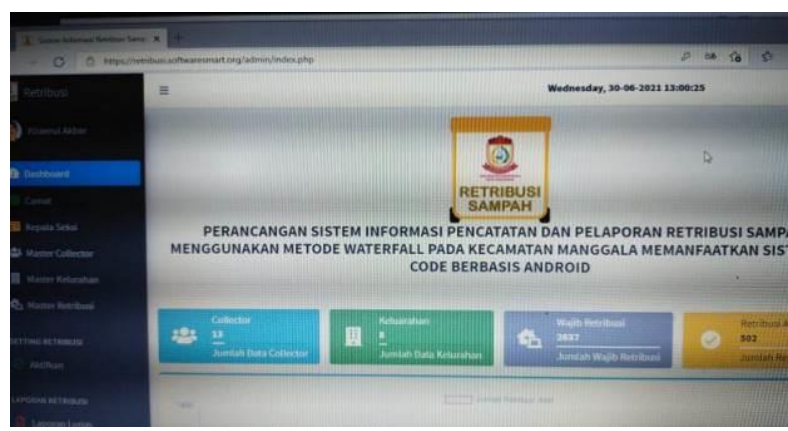

Gambar 3. Tampilan halaman dashboard sistem informasi
Pada halaman dashboard terdiri dari beberapa menu antara lain master kelurahan, master retribusi, master kolektor, seperti pada tampilan gambar 4,5 dan 6 .

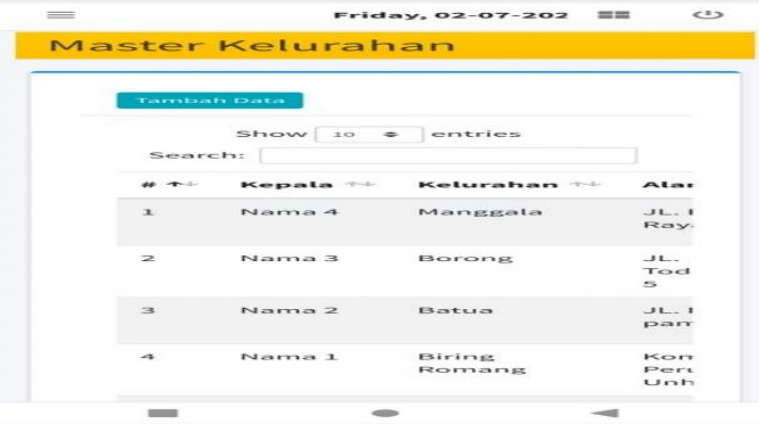

Gambar 4. Tampilan master kelurahan

Pada halaman ini menampilkan semua keurahan yang ada di wilayah Kecamatan Manggala.

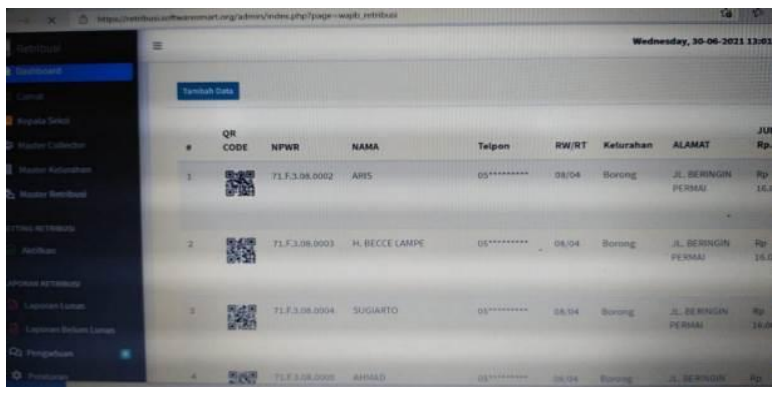

Gambar 5. Tampilan halaman master retribusi

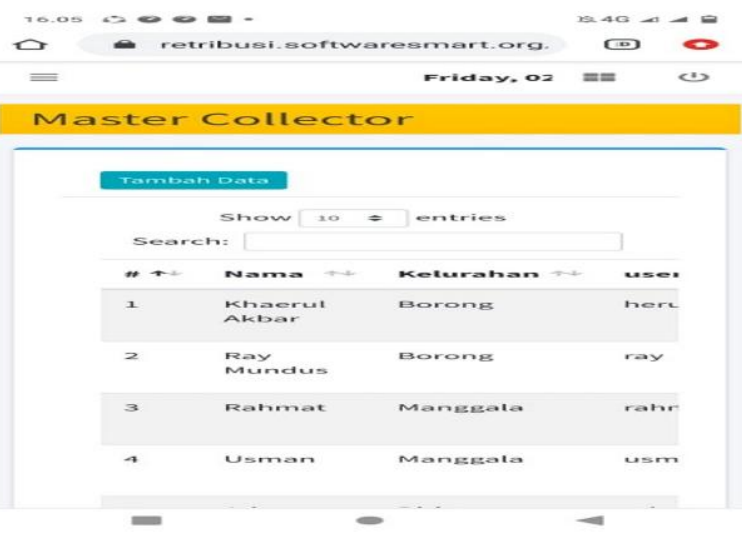

Gambar 6. Tampilan halaman master kolektor 
741 Pelatihan Pemanfaatan Sistem Informasi Pelaporan Retribusi Sampah - Nuraida Latif, Syaharullah Disa, Ratnawati, Agus Halid, Andi Sumardin, A.Yulia Muniar, Wisda

DOI: https://doi.org/10.31004/abdidas.v2i4.357

Pada halaman master kolektor, menampilkan nama-nama kolektor di tiap kelurahan. Setelah pemaparan materi selesai maka di lanjutkan sesi tanya jawab dan sebagai penutup di lakukan pemberian cendramata kepada Kasie Kebersihan \& Pertanaman Kecamatan Manggala, kemudian foto Bersama antara tim pengabdian Masysrakat STMIK AKBA dengan peserta pelatihan dari Kecamatan Manggala, seperti pada gambar 7 dan 8 .

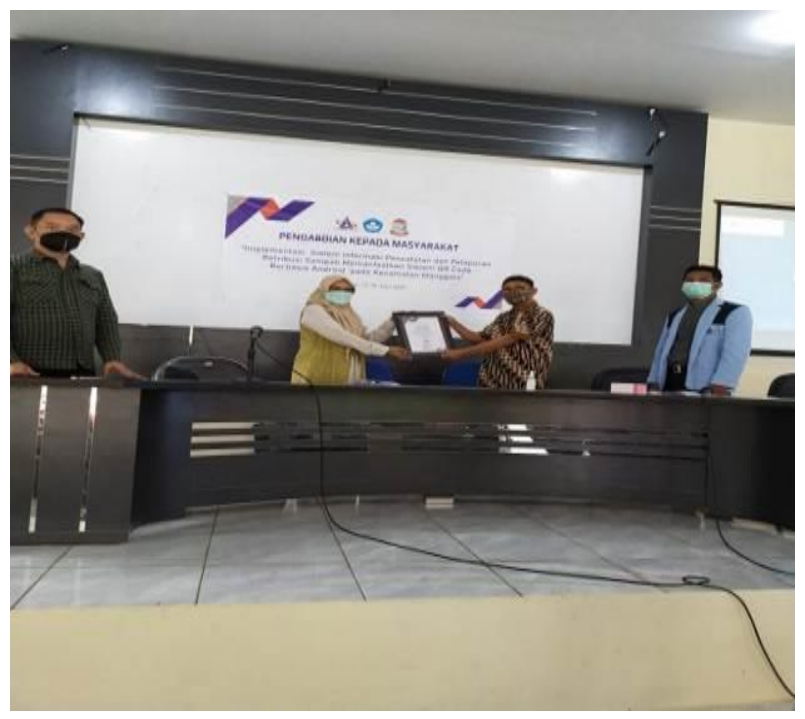

Gambar 7. Pemberian cendramata

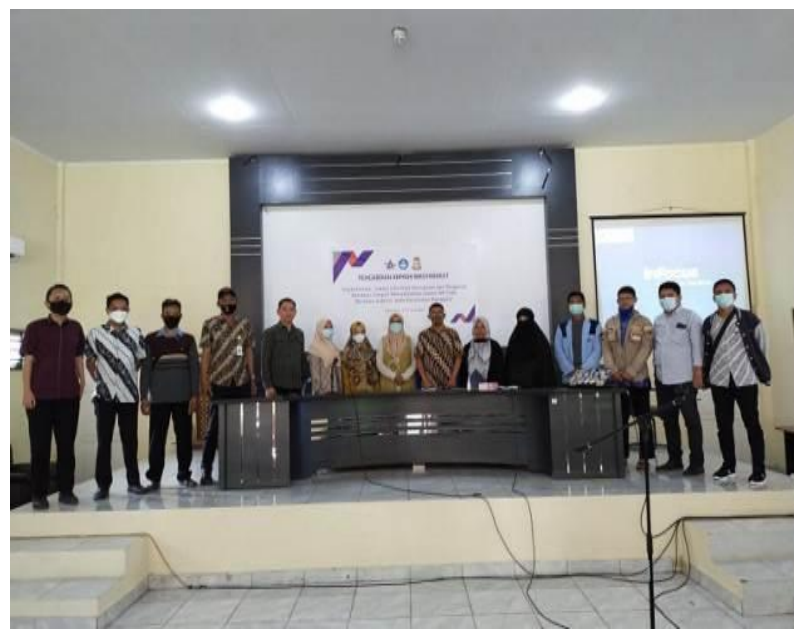

Gambar 8. Foto bersama tim pengabdian masyarakat dengan peserta

\section{Evaluasi Kegiatan}

Evalusai ini berupa pembagian kuisioner kepada peserta sebanyak 12 orang. Hasilnya sebagai berikut :

Tabel 1. Tabel kuisioner peserta

\begin{tabular}{|c|c|c|c|c|c|}
\hline No & Pernyataan & SS & $\mathrm{S}$ & TS & STS \\
\hline 1 & \begin{tabular}{lrr}
\multicolumn{2}{c}{ Saya merasa } & puas dengan \\
kegiatan & pengabdian \\
masyarakat & yang \\
dilakukan & Tim & STMIK \\
AKBA & &
\end{tabular} & 7 & 5 & & \\
\hline 2 & $\begin{array}{lr}\text { Sistem ini } & \text { sangat } \\
\text { membantu saya di bagian } \\
\text { kebersihan } & \text { dan } \\
\text { pertanaman } & \\
\end{array}$ & 12 & & & \\
\hline 3 & $\begin{array}{l}\text { Saya akan } \\
\text { mengimplementasikan } \\
\text { sistem ini di pelaporan } \\
\text { retriusi sampah Kec. } \\
\text { Manggala }\end{array}$ & 12 & & & \\
\hline 4 & $\begin{array}{l}\text { Pertanyaan yang saya } \\
\text { ajukan dapat direspon } \\
\text { dengan baik }\end{array}$ & 10 & 2 & & \\
\hline 5 & $\begin{array}{l}\text { Jika kegiatan ini } \\
\text { dilaksanakan Kembali } \\
\text { saya akan berpastisipasi } \\
\text { /terlibat }\end{array}$ & 12 & & & \\
\hline
\end{tabular}

Ket $:$ SS = Sangat Setuju, S=Setuju, TS=Tidak Setuju, STS=Sangat tidak setuju

Hasil evaluasi menunjukkan bahwa sistem yang di presentasikan pada Kantor Kecamatan Manggala sangat mendapat respon yang positif dari peserta pengabdian dilihat dari evaluasi yang diberikan nilai yang diberikan sangat setuju dan setuju terhadap apa yang telah dipresentasikan.

\section{SIMPULAN}

STMIK AKBA sebagai salah satu lembaga perguruan tinggi swasta berbasis teknologi informasi senantiasa bersinergi secara maksimal dalam melaksanakan program pengabdian kepada masyarakat khususnya dibidang teknologi 
742 Pelatihan Pemanfaatan Sistem Informasi Pelaporan Retribusi Sampah - Nuraida Latif, Syaharullah Disa, Ratnawati, Agus Halid, Andi Sumardin, A.Yulia Muniar, Wisda

DOI: https://doi.org/10.31004/abdidas.v2i4.357

informasi. Salah Satu program pengabdian masyarakat yang telah dilaksanakan yakni pemberian pelatihan pemanfaatan Sistem Informasi pelaporan retribusi sampah pada Kecamatan Manggala agar dapat diimplementasikan secara maksimal untuk membantu pegawai bagian kebersihan dan pertanaman Kecamatan Manggala untuk melayani masyarakat dalam penagihan retribusi sampah secara transparansi dan efisien.

Program pengabdian ini berjalan dengan baik yang dihadiri oleh pegawai Kecamatan Manggala sebagai peserta dan Dosen STMIK AKBA sebagai pemateri/pendamping serta beberapa mahasiswa STMIK AKBA sebagai tim dokumentasi. Program ini disambut dan diterima dengan baik oleh Kecamatan Manggala karena sistem informasi pelaporan retribusi sampah ini, sangat dibutuhkan dalam membantu pegawai bagian kebersihan dan pertanaman Kecamatan Manggala untuk melayani masyarakat dalam penagihan retribusi sampah secara transparansi dan efisien.

\section{UCAPAN TERIMA KASIH}

Ucapan Terima kasih kepada Lembaga Penelitian dan Pengabdian Kepada Masyarakat (P3M) STMIK AKBA yang telah mendanai kegiatan pengabdian kepada masyarakat di Kecamatan Manggala, sehingga kegiatan pengabdian ini dapat berjalan dengan baik.

\section{DAFTAR PUSTAKA}

Arifin, R., \& Latif, N. (2020). Sistem Informasi Pengelolaan Surat Menyurat Berbasis Web Pada Kantor Balai Latihan Masyarakat
Makassar. Inspiration: Jurnal Teknologi Informasi dan Komunikasi, 10(1), 68-76.

INGENIAS development kit: A visual multiagent system development environment. Proceedings of the International Joint Conference on Autonomous Agents and Multiagent Systems, AAMAS, 3(January 2014), 1629-1630.

Latif, N., \& Awaliah, N. (2020). Implementasi Sistem Informasi Geografis Layanan Publik Lingkup Kota Pare-Pare Berbasis Web. Jurnal Ilmiah Ilmu Komputer Fakultas Ilmu Komputer Universitas Al Asyariah Mandar, 6(2), 55-59.

Magdalena, H., Santoso, H., \& Rochmayani, K. (2019). Rekayasa Sistem Informasi Retribusi Sampah Berbasis Web untuk Optimalisasi Kinerja Bidang Pengelolaan Sampah. CogITo Smart Journal, 5(2), 294-307.

Makassar, W. (2011). Peraturan Daerah Kota Makassar. 1-19.

Pamularsih, E. (2020). Perancangan Sistem Pengolahan Data Iuran Sampah. 367-374.

Sangkala, S., \& Latif, N. (2015). Rekayasa Perangkat Lunak Mobile Commerce Berbasis Wireless Application Protocol (WAP) Pada PT. Anugrah Argon Medica. Inspiration: Jurnal Teknologi Informasi dan Komunikasi, 5(2).

Tamura, H. (2008). Sistem Informasi Pembayaran Sampah Dan Penjadalan Siskamling Dengan Sms Gateway (Studi Kasus Rt 006 Petukangan Utara). Journal of Chemical Information and Modeling, 53(9), 287. https://doi.org/10.1017/CBO97811074153 24.004. 